\title{
Carbenoxolone does not cross the blood brain barrier: an HPLC study \\ Yevgen Leshchenko ${ }^{2}$, Sergei Likhodii ${ }^{1}$, Wendy Yue ${ }^{1}$, William M Burnham ${ }^{1}$ and Jose L Perez Velazquez*2
}

\author{
Address: ${ }^{1}$ Department of Pharmacology, University of Toronto, Toronto, Ontario, Canada and ${ }^{2}$ Brain and Behaviour Programme and Division of \\ Neurology, Hospital for Sick Children, Department of Paediatrics and Institute of Medical Science, University of Toronto, Toronto, Ontario, \\ Canada \\ Email: Yevgen Leshchenko - lyevgen@sickkids.ca; Sergei Likhodii - sergei.likhodi@utoronto.ca; Wendy Yue - wen.yue@utoronto.ca; \\ William M Burnham - mac.burnham@utoronto.ca; Jose L Perez Velazquez* - jose-luis.perez-velazquez@sickkids.ca \\ * Corresponding author
}

Published: II January 2006

BMC Neuroscience 2006, 7:3 doi:10.1 I86/147/-2202-7-3
Received: 06 September 2005

Accepted: II January 2006

This article is available from: http://www.biomedcentral.com/I47/-2202/7/3

(c) 2006 Leshchenko et al; licensee BioMed Central Ltd.

This is an Open Access article distributed under the terms of the Creative Commons Attribution License (http://creativecommons.org/licenses/by/2.0), which permits unrestricted use, distribution, and reproduction in any medium, provided the original work is properly cited.

\begin{abstract}
Background: Carbenoxolone (CBX) is a widely used gap junctional blocker. Considering several reports indicating that transient gap junctional blockade could be a favourable intervention following injuries to central nervous tissue, and some current enthusiasm in studies using systemic injections of $C B X$, it is imperative to consider the penetration of $C B X$ into central nervous tissue after systemic administrations. So far, only very indirect evidence suggests that $C B X$ penetrates into the central nervous system after systemic administrations. We thus determined the amounts of $C B X$ present in the blood and the cerebrospinal fluid of rats after intraperitoneal administration, using high performance liquid chromatography

Results: CBX was found in the blood of the animals, up to 90 minutes post-injection. However, the cerebrospinal fluid concentration of $C B X$ was negligible.

Conclusion: Thus, we conclude that, most likely, CBX does not penetrate the blood brain barrier and therefore recommend careful consideration in the manner of administration, when a central effect is desired.
\end{abstract}

\section{Background}

Carbenoxolone (CBX), a derivative of 18-glycyrrhetinic acid [1], is a widely used drug which, in addition to being a mineralocorticoid agonist and inhibiting 11-beta hydroxysteroid dehydrogenase [2], also blocks gap junctional communication [these issues nicely reviewed in reference [3]]. There has been an increasing enthusiasm in the use of CBX in studies where gap junctional coupling has to be altered, both in vitro [4-6] and in vivo [7-11]. Some of these in vivo studies attribute a possible effect of $\mathrm{CBX}$ in the central nervous system (CNS) of the animals
$[8,11]$ after systemic administration, thus assuming CBX crosses the blood brain barrier. However, the only study that suggested that CBX crosses the blood brain barrier is the Jellinck et al. determination of the inhibition of 11beta-hydrysteroid dehydrogenase in brain after intraperitoneal (i.p.) injections [12].

To clarify this issue, we used a detection method based on high performance liquid chromatography (HPLC) [13], and assessed the drug concentration in blood and in cerebrospinal fluid (CSF) samples of adult rats injected intra- 


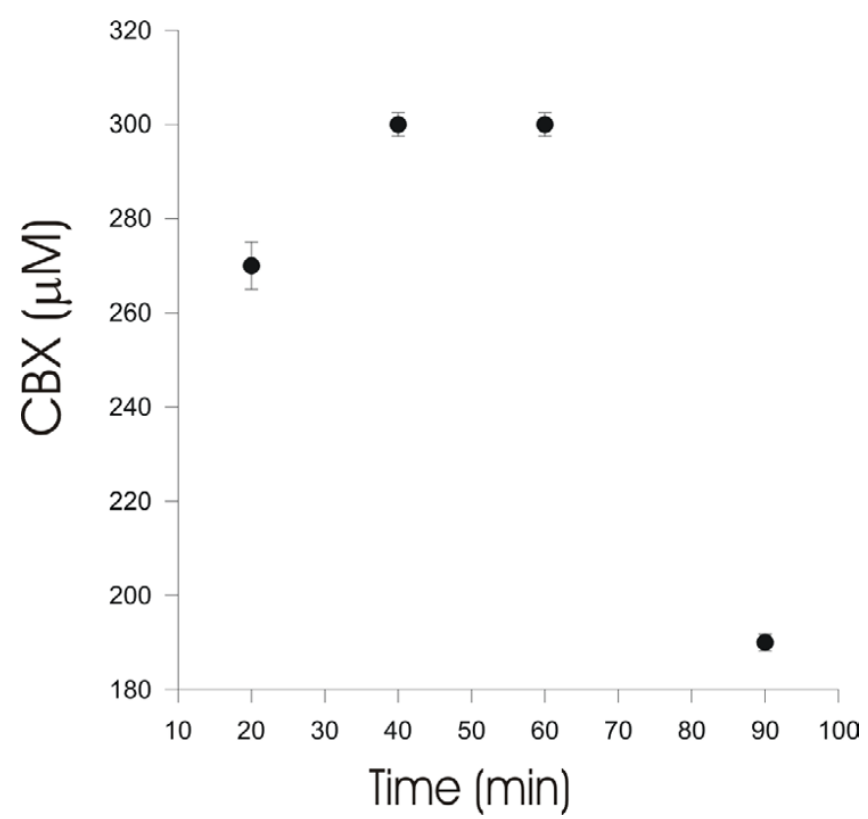

Figure I

Time course of $C B X$ detected in the plasma after an i.p injection of $50 \mathrm{mg} / \mathrm{Kg}$. Maximal plasma concentration (mean $+/-$ SD) was found between 40 -and 70 minutes post-injection.

peritoneally with CBX (50 mg/Kg). While CBX was found in the plasma, its concentration in CSF was insignificant.

\section{Results}

Following an i.p. injection of CBX (50 mg/Kg), blood samples were taken from the vein in the tail of the animal, and CSF samples collected from the cisterna magna. A total of 16 rats were used in this study. Figure 1 shows the HPLC-determined CBX concentration in the blood samples, at several time points. We note that, in plasma samples, we obtained about $15-20 \%$ of the theoretically estimated maximal CBX blood concentration (estimating a blood volume of $10 \%$ of body weight), that is, assuming all CBX was transferred to the circulation. However, one hour and a half post-injection, the concentration in blood had already dropped considerably to less than $200 \mu \mathrm{M}$. The concentration of CBX in CSF was negligible $(<1 \mu \mathrm{M})$ at all time points tested, therefore we conclude that there is no transfer from the circulation to the CSF. In previous studies, we found that other compounds that are lipid soluble can be detected by our HPLC system at similar levels in plasma and in the CSF, such as acetone [14].

\section{Discussion}

There is a current considerable interest in the possible roles of gap junctional communication in neuronal activity, and therefore a number of studies have used CBX as a gap junctional blocker and have attributed a central action of CBX after systemic administration. These studies include CBX effects on epileptiform activity $[8,15]$ or on stereotypic behaviours [11]. Nevertheless, the only evidence that indicated, albeit indirectly, that CBX penetrates the blood brain barrier, was that presented in Jellinck et al. [12]; however, this evidence is very indirect because the studied relied on the CBX inhibition of 11-beta hydroxysteroid dehydrogenase, a relatively indirect measurement. As well, brain tissue was homogenized for these studies, which will include blood vessels and other tissues. A clearer determination of CBX presence in tissue samples can be obtained from specific fluid samples with the HPLC method developed by Zhang [13].

That CBX was not found in CSF samples should not really be surprising, as this molecule is polar and relatively large $[1,3]$, and therefore we can conceive that it will be difficult to traverse the blood brain barrier. Hence, when looking for a central effect of CBX, a direct, intracranial administration will be more appropriate, using cannulae for example [9]. However, our determination of CBX in CSF samples still does not rule out completely the possibility of a very transient crossing of the blood brain barrier by the drug, if for instance, we envisage a situation in which CBX is concentrated in brain tissue with little spill over into the CSF. Because of the problems associated with determining drug presence in brain tissue, which would involve homogenisation of the tissue and thus bringing along arteries and CSF vessels, we did not attempt these analyses.

Considering current evidence that gap junctional blockers may have a beneficial CNS effect after traumatic injuries [5] or ischaemic insults [16,17], the issue of drug delivery could become of importance for possible therapeutic approaches. Hence, the creation of gap junctional ligands that traverse the blood brain barrier could be an important development. However, because of the breakdown of the blood brain barrier that occurs after traumatic/ischaemic, epileptic, or inflammation injury, a penetration into brain tissue can be expected in these conditions, consideration to be taken into account for possible therapeutic approaches.

\section{Conclusion}

Our results suggest that CBX does not penetrate the blood brain barrier after i.p. administration, even though the possibility of a transient residence into brain tissue cannot be ruled out by these analyses. Hence, intracerebral injections are strongly recommended if the study is concerned with possible brain effects of the drug. In addition, intracerebral administration circumvents the potential confounding factor of systemic effects, which may be mediated by mineralocorticoid receptor activation and could contribute to the observed results. 


\section{Methods}

Injections of CBX into animals and fluid withdrawal

CBX was purchased from Sigma. Male Long Evans rats (50-60 days old) were injected intraperitoneally (i.p.) with a dose of $50 \mathrm{mg} / \mathrm{Kg}$. Blood $(0.2 \mathrm{ml})$ was taken from the rat's tail vein, and CSF samples $(0.1 \mathrm{ml})$ were taken at several time points after the drug injection, by puncturing the cisterna magna using a syringe equipped with a $30 \mathrm{G}$ needle. Rats were anesthetized with halothane for all these procedures. The experiments were approved by the Hospital for Sick Children Animal care Committee

\section{High Performance Liquid Chromatography (HPLC)}

We used the Aiglent Hewlett Packard Model 1100 Series, High performance liquid chromatography (HPLC) system (Aiglent Technologies), equipped with a variable Wavelength ultraviolet-visible detector. We followed the HPLC method previously developed to determine carbenoxolone concentration [13], using acetonitrile as component $\mathrm{A}$ of the mobile phase, and potassium phosphate buffer solution ( $\mathrm{pH} 7.0$ ) as component $\mathrm{B}$. The mobile phase had a flow rate of $1.0 \mathrm{ml} / \mathrm{min}$ with a proportion $12 \%$ to $88 \%$ for components $\mathrm{A}$ and $\mathrm{B}$ of the mobile phase, respectively. Detection was performed with the UV detector at $254 \mathrm{~nm}$.

\section{Abbreviations}

CBX: carbenoxolone

CSF: cerebrospinal fluid

HPLC: high performance liquid chromatography

i.p.: intraperitoneal

\section{Acknowledgements}

Our work is supported by a grant from the Savoy Foundation and the Dean's Fund of the University of Toronto.

\section{References}

I. Davidson JS, Baumgarten JM: Glycyrrhetinic acid derivatives: a novel class of inhibitors of gap junctional intercellular communication: Structure-activity relationship. J Pharm Exper Therapeutics 1988, 246: I 104.

2. Sewell KJ, Shirly DG, Michael AE, Thompson A, Norgate DP, Unwin RJ: Inhibition of renal I I-beta-hydroxysteroid dehydrogenase in vivo by carbenoxolone in the rat and its relationship to sodium excretion. Clin Sci 1998, 95:435-443.

3. Rozental R, Srinivas M, Spray DC: How to close a gap junction channel: Efficacies and potencies of uncoupling agents. Methods Mol Biol 200I, I 54:447-476.

4. Bani-Yaghoub M, Underhill TM, Naus CCG: Gap junction blockage interferes with neuronal and astroglial differentiation ofmouse PI9 embryonal carcinoma cells. Dev Genetics 1999, 24:69-8I.

5. Frantseva MV, Kokarovtseva L, Naus CCG, Carlen PL, MacFabe D, Perez Velazquez JL: Specific gap junctions enhance the neuronal vulnerability to brain traumatic injury. J Neurosci 2002 , 22:644-653.

6. Ross FM, Gwyn P, Spanswick D, Davies SN: Carbenoxolone depresses spontaneous epileptiform activity in the CAI region of rat hippocampal slices. Neuroscience 2000, 100:789-796.

7. Szente M, Gajda Z, Said Ali K, Hermesz E: Involvement of electrical coupling in the in vivo ictal epileptiform activity induced by 4-aminopyridine in the neocortex. Neuroscience 2002, I 1 5:1067-1078.

8. Gareri P, Condorelli D, Belluardo N, Russo E, Loiacono A, Barresi V, Trovato-Salinato A, Mirone MB, Ibbadu GF, De Sarro G: Anticonvulsant effects of carbenoxolone in genetically epilepsy prone rats. Neuropharmacology 2004, 47:1205-1216.

9. Gareri P, Condorelli D, Belluardo N, Citraro R, Barresi V, TrovatoSalinato A, Mudò G, Ibbadu GF, Russo E, De Sarro G: Antiabsense effects of carbenoxolone in two genetic animal models of absence epilepsy (WAG/Rij rats and Ih/lh mice). Neuropharmacology 2005 in press.

10. Gajda Z, Gyengési E, Hermesz E, Said Ali K, Szente M: Involvement of gap junctions in the manifestation and control of the duration of seizures in rats in vivo. Epilepsia 2003, 44:1596-1600.

II. Moore H, Grace AA: A role for electrotonic coupling in the striatum in the expression of dopamine receptor-mediated sterotypies. Neuropsychopharmacology 2002, 27:980-992.

12. Jellinck PH, Monder C, McEwen BS, Sakai RR: Differential inhibition of I $\beta$-hydroxysteroid dehydrogenase by carbenoxolone in rat brain regions and peripheral tissues. I Steroid Biochem Molec Biol 1993, 46:209-2I3.

13. Zhang Y: Determination of furazolidone, carbenoxolone sodium and berberine hydrochloride in wei kang tablets by reversed-phase high performance liquid chromatography (RP-HPLC). Chinese J Chromatography 2002, 20:350-352.

14. Likhodii S, Sebanesku I, Cortez M, Murphy P, Snead C, Burnham M: Anticonvulsant properties of acetone, a brain ketone elevated by the ketogenic diet. Ann Neurol 2003, 54:219-226.

15. Hosseinzadeh H, Nassiri AM: Anticonvulsant, sedative and muscle relaxant effects of carbenoxolone in mice. BMC Pharmacol 2003, 3:3-13.

16. Saito R, Graf R, Hubel K, Fujita T, Rosner G, Heiss WD: Reduction of infarct volume by halothane: effect on cerebral blood flow or perifocal spreading depression-like depolarizations. J Cereb Blood Flow Metab 1997, I 7:857-864.

17. Perez Velazquez JL, Frantseva MV, Naus CCG: Gap junctions and neuronal injury: protectants or executioners? The Neuroscientist 2003, 9:5-9.

\section{Publish with Biomed Central and every scientist can read your work free of charge}

"BioMed Central will be the most significant development for disseminating the results of biomedical research in our lifetime. "

Sir Paul Nurse, Cancer Research UK

Your research papers will be:

- available free of charge to the entire biomedical community

- peer reviewed and published immediately upon acceptance

- cited in PubMed and archived on PubMed Central

- yours - you keep the copyright

Submit your manuscript here:

http://www.biomedcentral.com/info/publishing_adv.asp 